\title{
Prognostic value of RT-PCR tyrosinase detection in peripheral blood of melanoma patients
}

\author{
Esmeralda Carrillo $^{\mathrm{a}, \mathrm{b}}$, José Prados ${ }^{\mathrm{a}, \mathrm{b}}$, Juan Antonio Marchal ${ }^{\mathrm{a}, \mathrm{c}}$, Houria Boulaiz ${ }^{\mathrm{a}, \mathrm{c}}$, Antonio Martínez $^{\mathrm{a}, \mathrm{c}}$, \\ Fernando Rodríguez-Serrano ${ }^{\mathrm{a}, \mathrm{c}}$, Octavio Caba $^{\mathrm{a}, \mathrm{b}}$, Salvio Serrano ${ }^{\mathrm{d}}$ and Antonia Aránega ${ }^{\mathrm{a}, \mathrm{b}, *}$ \\ ${ }^{a}$ Biopathology and Medicine Regenerative Institute (IBIMER), Granada, Spain \\ ${ }^{\mathrm{b}}$ Department of Anatomy and Human Embriology Faculty of Medicine, University of Granada, E-18012 Granada, \\ Spain \\ ${ }^{\mathrm{c}}$ Department of Health Sciences, University of Jaén, E-23071 Jaén, Spain \\ ${ }^{\mathrm{d}}$ Department of Dermatology, Faculty of Medicine, University of Granada, E-18012 Granada, Spain
}

\begin{abstract}
Malignant melanoma (MM) prognosis has been related to tumour thickness and clinical stage and metastasis risk has been associated with presence of tumour cells in peripheral blood. The aim of this study was to determine the relationship between presence of tyrosinase in peripheral blood of MM patients and their clinical prognosis. Blood samples from $58 \mathrm{MM}$ patients (stage I-IV) were analysed, using RT-PCR assay to detect tyrosinase mRNA. The results showed that positive RT-PCR assay for tyrosinase were significantly associated with clinical status and tumour thickness. After a median follow-up of 24 months, RT-PCR results were found to be significant correlated with recurrence $(p<0.05)$ and clinical stage III $(p<0.05)$. Separate analysis of stage III tumours to determine the prognostic value of tyrosinase presence in peripheral blood showed an overall 24-month survival rate of $70 \%$ in the RT-PCR negative group versus $10 \%$ in the positive group $(p<0.02)$. These results suggest that detection of circulating melanoma cells may be especially relevant in stage III patients, in whom RT-PCR positivity defines a subpopulation at high risk of recurrence.
\end{abstract}

\section{Introduction}

The incidence rate of malignant melanoma (MM) has increased more than that of any other malignancy among white populations over the past 15 years [1] The development of metastasis is the leading cause of mortality in MM patients [2,3] Although there is no effective systemic therapy for the treatment of metastatic $\mathrm{MM}$, its early detection can improve clinical assessment of the progression, metastatic potential and response to therapy of the tumour [4]. The identification of a biological factor that could serve to predict the clinical progression of MM has been extensively researched.

*Corresponding author: Antonia Aránega Jiménez, Tel.: +34 958243534; Fax: +34 958246296; E-mail: esmeral@ugr.es.
Several markers of MM have been proposed to date and the most widely used have been tyrosinase (TYR) and its related proteins (TYRPs). Tyrosinase is a key enzyme in melanin biosynthesis and is exclusively expressed in melanocytes and melanoma cells $[5,6]$. Detection of tyrosinase enzyme by reverse transcriptasepolymerase chain reaction (RT-PCR) assay has been used to detect occult melanoma cells in blood and lymph nodes of melanoma patients [7-9]. A pivotal study by Smith et al. [10], established the usefulness of RT-PCR amplification of tyrosinase mRNA for detecting circulating melanoma cells (CMCs). Our group previously used this method to demonstrate presence of CMCs in patients with melanoma at different clinical stages [11]. There is little information on the clinical significance of tyrosine mRNA detection in peripheral blood of MM patients and conflicting data have been 
reported [12]. In this context, it is accepted that presence of CMCs is correlated with the clinical stage of patients and that detection of these cells in patients with early-stage disease may indicate a high risk of metastasis and a lower probability of overall survival [13]. Recent studies described tyrosinase RT-PCR results as a potentially useful molecular marker that may provide an early indication of therapy effectiveness [14]. However, other authors found no relationship between positive PCR for tyrosinase and disease-free or overall survival [15]. Therefore, the prognostic value of the tyrosinase enzyme test remains controversial.

We report results of tyrosinase detection by RT-PCR in peripheral blood samples from $58 \mathrm{MM}$ patients in all clinical stages (I, II, III or IV). The aim of this study was to determine the clinical relevance of this procedure, exploring the relationship between presence of tyrosinase in peripheral blood of MM patients and their clinical stage and prognosis.

\section{Materials and methods}

\subsection{Patients}

Blood samples were obtained at the Dermatology Service of the University Hospital of Granada from 58 consecutively selected MM patients at time of primary tumour diagnosis or at relapse. Clinical stage was classified according to AJCC recommendations: primary cutaneous tumour (stages I and II), regional skin or lymph node metastasis (stage III) or distant metastatic tumour dissemination (stage IV). All stage I-III patients were visited every 4 months during the first 2 years after the diagnosis and every 6 months thereafter. Follow-up sessions included clinical history, physical examination, blood cell count and biochemistry allowed to carry out the disease control and to determine the presence or the absence of relapse. In each session simple blood was obtained to determine the presence of CMCs by means of RT-PCR. All patients gave written consent after receiving information on the purpose of the blood sampling. The outcome of the PCR analyses had no influence on treatment. Blood samples from 10 healthy subjects or patients without melanoma were used as negative controls and analyzed under identical conditions.

\subsection{Blood collection and RNA isolation}

Samples of peripheral venous blood $(10 \mathrm{ml})$ from each patient were collected in five tubes containing ethylenediamine tetraacetic acid (EDTA), stored at $4^{\circ} \mathrm{C}$, and processed on ice within 2-4 h. After centrifugation $(650 \mathrm{xg}$ for $5 \mathrm{~min}$ ) the serum was collected and treated with $45 \mathrm{ml}$ diethyl pyrocarbonate-treated water (H20-DEP) and $5 \mathrm{ml} \mathrm{PBS} \mathrm{(x} \mathrm{10),} \mathrm{and} \mathrm{centrifuged}$ at $650 \mathrm{x}$ g for $5 \mathrm{~min}$ several times until a white pellet (PBLC) was obtained. Total RNA was isolated from the cell fraction with the IsoRNA-Fast Plus kit (Master Diagnafistica, Granada, Spain) following the manufacturer's instructions. Yield and purity of the RNA were determined by ultraviolet spectroscopy.

\subsection{Oligonucleotide primers}

Oligonucleotide primers specific for tyrosinase were designed according to Smith et al. [10]. The primers 5' TTG GCA GAT TGT CTG TAG CC (sense) and 3' AGG CAT TGT GCA TGC TGC TT (antisense) were chosen to amplify a 284-base pair (bp) fragment of the tyrosinase cDNA. Integrity of the RNA was determined using primers 5' ATG GAT GAT GAT ATC GCC GCG (sense) and 3' TCT CCA TGT CGT CCC AGT TG (antisense) that amplified a 248-bp fragment of $\beta$-actin [16].

\subsection{RT-PCR assay}

Reverse transcription (RT) was performed using $1 \mu \mathrm{g}$ of total RNA. First-strand cDNA was generated with $0.4 \mu \mathrm{mol} / \mathrm{L}$ of random hexamers, $1 \mathrm{mmol} / \mathrm{L}$ of each deoxynucleotide triphosphate (dNTP), 24 units of avian myeloblastosis virus RT (Promega, Madison, Wisconsin, USA) and 40 units of RNasin (Promega) in a final volume of $20 \mu \mathrm{L}$ of RT buffer. After incubation at $42^{\circ} \mathrm{C}$ for $18 \mathrm{~min}$ and $94^{\circ} \mathrm{C}$ for $5 \mathrm{~min}$ (Linus Autocycler 32, Cultek S.L. Madrid, Spain), samples were resuspended in $80 \mu \mathrm{L}$ of H20-DEP. For the first PCR round, $10 \mu \mathrm{L}$ of the RT products were diluted to $100 \mu \mathrm{L}$ (RT buffer) in a mixture with a final concentration of $2.0 \mathrm{mmol} / \mathrm{L}$ $\mathrm{MgC} 12,200 \mu \mathrm{mol} / \mathrm{L}$ dNTP and $1 \mu \mathrm{mol} / \mathrm{L}$ of each tyrosinase primer. After a hot start $\left(2 \mathrm{~min}\right.$ at $\left.94^{\circ} \mathrm{C}\right), 2$ units of Taq polymerase (Boehringer Mannheim, Germany) were added, followed by 30 cycles at $94^{\circ} \mathrm{C}$ for $1 \mathrm{~min}, 58^{\circ} \mathrm{C}$ for $2 \mathrm{~min}, 72^{\circ} \mathrm{C}$ for $3 \mathrm{~min}$ and $72^{\circ} \mathrm{C}$ for 7 $\min$. For the analysis, $70 \mu \mathrm{L}$ of the reaction product was run on a $2 \%$ agarose gel and stained with ethidium bromide. The gel was viewed and photographed under ul- 
traviolet light. Specificity of the amplified product was established by restriction enzyme digestion. Quality of the mRNA was controlled by PCR for $\beta$-actin [16]. Lymph node metastasis from an MM patient was used as positive control.

\subsection{Statistical analysis}

Two variables were included in the data analysis: clinical stage and RT-PCR results. Clinical stage (I, II, III and IV) was analyzed as a discrete variable. RT-PCR results for tyrosinase mRNA were classified as positive or negative. A two-tailed Fischer's exact test was used to assess the association between RT-PCR results and clinical stage. The relationship among RT-PCR results, clinical stage and overall survival were evaluated in all patients. The association between RT-PCR and overall survival was also determined within each stage [17]. Survival time was defined as the period from blood extraction for PCR analysis to death or censoring. Patient survival was evaluated using the Kaplan Meier method [18] and survival comparisons among groups were performed using the log rank test [18]. Proportional hazards analysis was used to obtain maximum likelihood estimates of relative risks and their $95 \%$ confidence intervals in univariate and multivariate analyses [20,21] and to adjust for potential confounding effects. Parameters significant at the $P=0.05$ level in univariate analysis were included in a multiple proportional hazards model. Software for analysis was STAT (STATA Corp, College Station, TX, 1997).

\section{Results}

\subsection{Patient characteristics}

The study included 58 patients with $\mathrm{MM}$ at clinical (AJCC) stages I-II in 14 patients, stage III in 28 patients and stage IV in 16 patients. Patients had a median age of 50 years (range, 24-87 years) and 56.9\% were female. Patient characteristics are reported in Table 1.

\subsection{RT-PCR results, clinical stage and thickness}

According to RT-PCR findings, tyrosinase was detected in peripheral blood from 14 out of the $16 \mathrm{MM}$ patients $(88 \%)$ with metastatic disease (stage IV); the two remaining stage IV patients had a surgically excised isolated metastatic site with no evidence of clinical disease at the time of blood extraction. CMCs were
Table 1

Clinical characteristics of 58 patients with malignant melanoma

\begin{tabular}{lc}
\hline Characteristics & No. of patients \\
\hline Sex & \\
Male & 25 \\
Female & 33 \\
Median age, years (range) & $50(24-87)$ \\
Primary site & \\
Upper extremities & 9 \\
Lower extremities & 24 \\
Trunk & 14 \\
Head and neck & 11 \\
Clinical stage & \\
Stage I and II & 14 \\
Stage III & 28 \\
Stage IV & 16 \\
\hline
\end{tabular}

Table 2

RT-PCR results by stage

\begin{tabular}{lrrrrrr}
\hline & Total & \multicolumn{2}{c}{$\begin{array}{c}\text { RT-PCR } \\
\text { Positive }\end{array}$} & & \multicolumn{2}{c}{$\begin{array}{c}\text { RT-PCR } \\
\text { Negative }\end{array}$} \\
\cline { 3 - 4 } \cline { 6 - 7 } \cline { 5 - 6 } & & No & $\%$ & & No & $\%$ \\
\hline Stage I-II & 14 & 2 & 14 & & 12 & 86 \\
$<1.0 \mathrm{~mm}$ & 10 & 2 & & & 8 & \\
$1.1-4 \mathrm{~mm}$ & 3 & 0 & & & 3 & \\
$>4 \mathrm{~mm}$ & 1 & 0 & & & 1 & \\
Stage III & 28 & 20 & 71 & & 8 & 29 \\
$<1.0 \mathrm{~mm}$ & 4 & 1 & & & 3 & \\
$1.1-4 \mathrm{~mm}$ & 16 & 13 & & & 3 & \\
$>4 \mathrm{~mm}$ & 8 & 6 & & & 2 & \\
Stage IV & 16 & 14 & 88 & & 2 & 12 \\
\hline
\end{tabular}

also detected in the blood of two of the 14 patients at stage I-II (14\%) and in 20 of the 28 patients at stage III $(71 \%)$. All negative controls were negative for tyrosinase mRNA in the RT-PCR assay. The statistical analysis showed that the RT-PCR results were significantly associated with clinical status $(p<0.001)$ and tumour thickness $(p<0.002)$ (Table 2$)$ but not with primary site or patient gender.

\subsection{RT-PCR results and prognosis}

After a median follow-up of 24 months (range, 3-48 months), in which RT-PCR test were realized, risk of relapse was evaluated in all 58 patients. All stage I-II patients underwent complete resection of primary tumour; $50 \%(6 / 12)$ of stage I-II patients with negative RT-PCR test relapsed compared with $100 \%$ of patients $(2 / 2)$ with positive PCR result. Stage III patients received postsurgical adjuvant chemotherapy; 85\% (17/20) of RT-PCRpositive stage III patients relapsed versus $25 \%(2 / 8)$ of RT-PCR-negative patients. Neither of the two RTPCR-negative stage IV patients had the disease at 24 months, whereas $93 \%$ (13/14) of the RT-PCR-positive stage IV patients relapsed (Table 3). X2 univariate anal- 
Stage III

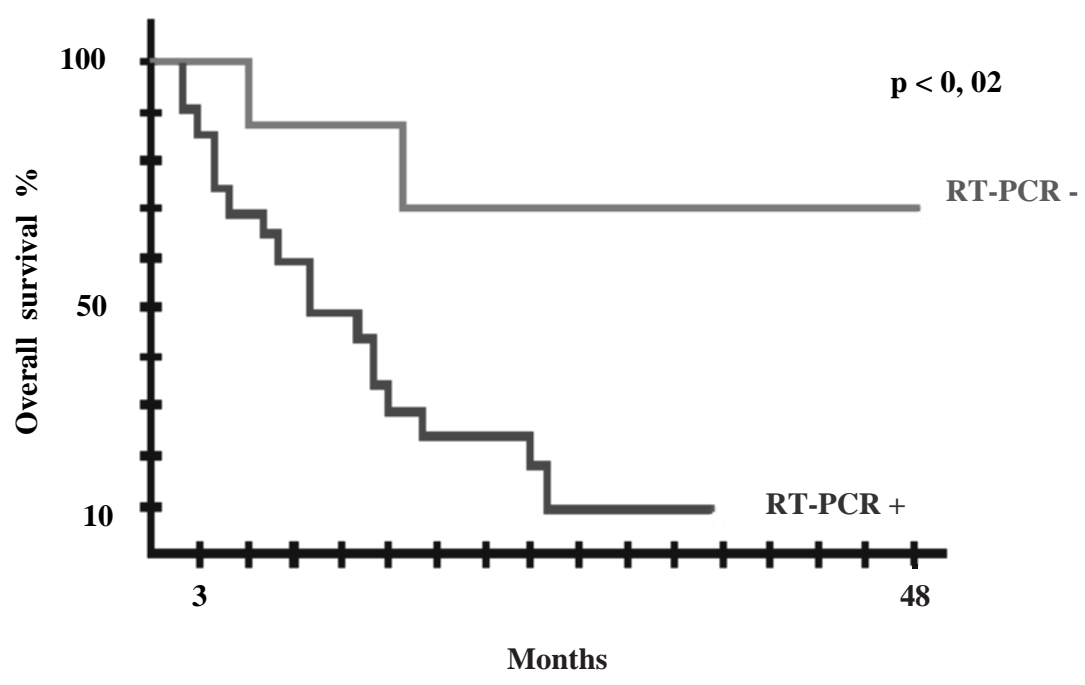

Fig. 1. Overall survival (OS) according to tyrosinase mRNA in blood in stage III patients. OS was calculated by Kaplan-Meier method.

Table 3

RT-PCR Results and Relapse in stage I-IV patients

\begin{tabular}{|c|c|c|c|c|c|}
\hline & \multirow[t]{2}{*}{ Total } & \multicolumn{2}{|c|}{ Relapse } & \multicolumn{2}{|c|}{ Non-Relapse } \\
\hline & & $\mathrm{N}^{\mathrm{O}}$ & $\%$ & $\mathrm{~N}^{\mathrm{O}}$ & $\%$ \\
\hline \multicolumn{6}{|l|}{ Stage I-II } \\
\hline $\mathrm{RT}^{-\mathrm{PCR}^{+}}$ & 2 & 2 & 100 & 0 & 0 \\
\hline RT-PCR ${ }^{-}$ & 12 & 6 & 50 & 6 & 50 \\
\hline \multicolumn{6}{|l|}{ Stage III } \\
\hline RT-PCR $^{+}$ & 20 & 17 & 85 & 3 & 15 \\
\hline RT-PCR ${ }^{-}$ & 8 & 2 & 25 & 6 & 75 \\
\hline \multicolumn{6}{|l|}{ Stage IV } \\
\hline RT-PCR $^{+}$ & 14 & 13 & 85 & 3 & 15 \\
\hline RT-PCR ${ }^{-}$ & 8 & 2 & 25 & 6 & 75 \\
\hline \multicolumn{6}{|l|}{ Total } \\
\hline $\mathrm{RT}^{\mathrm{P}} \mathrm{PCR}^{+}$ & 36 & 32 & 89 & 4 & 11 \\
\hline RT-PCR ${ }^{-}$ & 22 & 8 & 36 & 14 & 64 \\
\hline
\end{tabular}

ysis showed that RT-PCR results were significantly correlated with recurrence $(p<0.05)$ and clinical stage III $(p<0.05)$. No correlation was observed between recurrence and sex, age, histology, Breslow classification or primary site. In a separate analysis of stage III tumours to determine the prognostic value of melanoma cell presence in peripheral blood, overall 24-month survival was $70 \%$ in the RT-PCR-negative group versus $10 \%$ in the positive group $(p<0.02)$ (Fig. 1$)$. The two significant factors according to the univariate analysis (stage and RT-PCR status) were subjected to a multivariate analysis. A logistic regression model with PCR as dependent variable and stage, histology and thickness as independent variables yielded the following results, taking results for Stage I-III patients as reference: the likelihood that a stage III patient was RT-PCR pos- itive for tyrosinase mRNA was 15 (95\% CI: 2.7-94.6) and that a stage IV patient was positive was $42(95 \%$ CI: 5.1-345.1).

\section{Discussion}

It has recently been suggested that RT-PCR detection of tyrosinase mRNA in peripheral blood may be useful for establishing the prognosis of patients with $\mathrm{MM}$, although published results have been inconsistent. This hypothesis is based on the fact that detection of CMCs in peripheral blood indicates their mobilization from the site of the primary lesion via the peripheral blood. Some researchers reported a significant correlation between PCR positivity and clinical outcome but others observed no such relationship [13, 22]. The present study demonstrates that tyrosinase detection can be used as a molecular marker in the blood of MM patients. This marker is correlated with clinical stage (the most widely used MM prognostic system) and thickness, and may be useful for establishing the prognosis in these patients.

The detection of minimal residual disease by PCR amplification of specific tumour cell abnormalities has been widely used in haematologic malignancies as a useful tool for treatment response assessment and patient follow-up [23-26]. RT-PCR was recently used to detect malignant cells in peripheral blood of solid tumour patients [9]. Tyrosinase is specifically expressed 
in melanocytes or melanoma cells. Since melanocytes do not circulate, detection of tyrosinase mRNA in blood indicates presence of melanoma cells. Numerous authors have determined the percentage of CMC-positive MM patients using tyrosinase as marker, but results have ranged widely from $6 \%$ to $59 \%[27,28]$ In the present study, $62 \%$ of MM patients showed RT-PCR positivity, a higher percentage than in other studies with similar sample size [29] We also found a significant association between clinical stage of disease and RT-PCR status. CMCs were detected in a large majority of the patients with clinical metastasis, and in a progressively lower proportion in PCR-detected CMCs with lower stages of the disease. This correlation is of special relevance, because clinical stage is the main clinical datum used for the prognosis [29-31]. Similar findings were published by authors using multiple marker RTPCR assays [32-35], who found that most stage II, III and IV patients presented CMCs. Among the markers used, tyrosinase showed the strongest correlation with disease stage.

Detection of melanoma cells in peripheral blood has been correlated with clinical disease-free period In patients with an advanced stage of the disease, a positive test has also been related to lower patient survival [31] and presence of visceral metastasis [36]. However, other authors found no correlation between these variables [37,38]. Unfortunately, the heterogeneity of published series hampers direct comparison among published results. The present study demonstrated a statistically significant correlation between recurrence and RT-PCR results $(p<0.05)$. Moreover, a distinct clinical evolution was observed in stage III patients according to their RT-PCR status, with higher recurrence rates (17/20 vs. $2 / 8)$ and worse actuarial DFS in RT-PCRpositive patients. In fact, RT-PCR status was the only independent prognosis factor in the multivariate analysis. In contrast, our results could not show a significant correlation between the patients prognosis of stages III and the positive RT-PCR. It has been hypothesised that cells shed from these early lesions may be able to extravasate but lack additional properties required for the multistep process of metastatic dissemination [39]. However, a study of a larger sample of positive patients with a longer follow-up period is required to confirm our findings in these patients.

\section{Conclusion}

In conclusion, these results demonstrate a statistically significant association between malignant melanoma stage and RT-PCR detection of CMCs in peripheral blood. The outcome analysis showed a poorer prognosis in the group of patients with metastastic disease and detectable CMCs. This detection may be of special relevance in the prognosis of stage III patients, in whom positive RT-PCR detection appears to define a group at high risk of recurrence. Further research is warranted to develop protocols for the use of RT-PCR detection of CMCs in the prognosis of patients with melanoma, in the early detection of recurrence, and in clinical trials on the efficacy of systemic therapies.

\section{Acknowledgments}

We thank the staff of the Dermatology Service at the University Hospital of Granada for providing the blood samples and Ms $\mathrm{M}^{\mathrm{a}}$ Jesús Moreno for her competent technical assistance. This study was supported by the Fondo de Investigación Sanitaria de la Seguridad Social (FIS), Spain through no. PI041372.

\section{References}

[1] T.M. Johnson, O.M. Dolan, T.A. Hamilton, M.C. Lu, N.A. Swanson and L. Lowe, Clinical and histologic trends of melanoma, J. Am. Acad. Dermatol. 38 (1998), 681-686.

[2] G. Palmieri, M. Strazzullo, P.A. Ascierto, S.M.R. Satriano, A. Daponte and G. Castello, Polymerase chain reaction-based detection of circulating melanoma cells as an effective marker of tumor progression, J. Clin. Oncol. 17 (1999), 304-311.

[3] A. Petro, J. Schwartz and T. Johnson, Current melanoma staging, Clin. Dermatol. 22 (2004), 223-227.

[4] J.F. Thompson, R.A. Scolyer and F. Kefford, The Lancet 365 (2005), 687-701.

[5] Z. Battayani, J.J. Grob, L. Xerri, C. Noe, H. Zarour, G. Houvaenenghel, J.R. Delpero, D. Birmbaum, J. Hassoun and J.J. Bonerandi, Polymerase chain reaction detection of circulating melanocytes as a prognostic marker in patients with melanoma, Arch. Dermatol. 131 (1995), 443-447.

[6] D.S. Hoon, Y. Wang, P.S. Dale, A.J. Conrad, P. Shmid, D. Garrison, C. Kuo, L.J. Foshag, A.J. Rizze and D.L. Morton, Detection of occult melanoma cells in blood with a multiplemarker polymerase chain reaction assay, J. Clin. Oncol. 13 (1995), 2109-2116.

[7] F.A. Jung, A.C. Buzaid, M.I. Ross, K.V. Woods, J.J. Lee, M. Albitar and E.A. Grimm, Evaluation of tyrosinase mRNA as a tumor marker in the blood of melanoma patients, J. Clin. Oncol. 15 (1997), 2826-2831.

[8] A. Lukowsky, B. Bellmann, A. Ringk, H. Winter, H. Audring, S. Fenske and W. Sterry, Detection of melanoma micrometastases in the sentinel lymph node and in nonsentinel nodes by tyrosinase polymerase chain reaction, J. Invest. Dermatol. 113 (1999), 554-559.

[9] R.A. Ghossein and S. Bhattacharya, Molecular detection and characterisation of ciruclating tumour cells and micrometastases in solid tumours, Eur. J. Cancer 36 (2000), 1681-1694. 
[10] B. Smith, P. Selby, J. Southgate, J. Southgate, K. Pittman, C. Bradley and G.E. Blair, Detection of melanoma cells in peripheral blood by means of reverse transcriptase and polymerase chain reaction, Lancet 338 (1991), 1227-1229.

[11] E. Carrillo, J. Prados, C. Melguizo, J.A. Marchal, C. Vélez, S Serrano, H. Boulaiz, J.A. Mérida and A. Aranega, R-T PCR Detection of circulating tumor cells in patients with melanoma: Correlation with clinical stage, tumor thickness and histologic type, Pathol. International 52 (2002), 295-300.

[12] P. Quanglino, P. Savoia, S. Osella-Abat and M.G. Bernengo, RT-PCR tyrosinase expression in the peripheral blood of melanoma patients, Expert. Rev. Mol. Diagn. 4 (2004), 727741.

[13] H. Gogas, G. Kefala, D. Bafaloukos, K. Frangia, A. Polyzos, D. Pectasides, D. Tsoutsos, P. Panagiotour, J. Ioannovich and D. Loukopoulos, Prognostic significance of the sequential detection of circulating melanoma cells by RT-PCR in high risk melanoma patients receiving adjuvant interferon, Br.J. Cancer 87 (2002), 181-186.

[14] O. Bitisik, H. Camlica, D. Duranyildiz, F. Tas, S. Kuruful, and N. Dalay, Detection of circulating melanoma cells by a twomarker polymerase chain reaction assay in relation to therapy, J. Biochem. Mol. Biol. 36 (2003), 173-178.

[15] G. Palmieri, P.A. Ascierto, F. Perrone, S.M. Satriano, A. Ottaiano, A. Daponte, M. Napolitano, C. Caraco, N. Mozzillo, M.T. Melucci, A. Cossu and F. Tanda, Prognostic value of circulating melanoma cells detected by reverse transcriptasepolymerase chain reaction, J. Clin. Oncol. 21 (2003), 767773.

[16] E. Carrillo, J.A. Marchal, J. Prados, C. Melguizo, C. Vélez, N. Arena, L. Alvarez, S. Serrano and A. Aránega, Optimization of the tyrosinase mRNA probe to detect circulating melanocytes with reverse transcription and polymerase chain reaction, Cell Mol. Biol. 44 (1998), 1247-1252.

[17] R.A. Ghossein, D. Coit, M. Brennan, Z.F. Zhang, Y. Wang, S. Bhattacharya, A. Houghton and J. Rosai, Prognostic significance of peripheral and bone marrow tyrosinase mRNA in malignant melanoma, Clin. Cancer Res. 4 (1998), 419-428.

[18] E.L. Kaplan and P. Meier, Nomparametric estimation from incomplete observations, J. Am. Stat. Assoc. 53 (1957), 457481.

[19] R. Peto, M.C. Pike, P. Armitage, N.E. Breslow, D.R. Cox, S.V. Howard, N. Mantel, K. McPherson, J. Peto and P.J. Smith, Design and analysis of randomized clinical trials requiring prolonged observation of each patient. II. Analysis and examples, Br. J. Cancer 35 (1977), 1-39.

[20] D.R. Cox, Regression models and lifie tables, J. R. Stat. Soc. Ser. B. 34 (1972), 187-220.

[21] D.R. Cox, Partial likelihood, Biometrika 62 (1975), 269-279.

[22] D.S. Hoom, P. Bostick, C. Kuo, T. Okamoto, H.J. Wang, R. Elashoff and D.L. Morton, Molecular markers in blood as surrogate prognostic indicators of melanoma recurrence, Cancer Res 20 (2000), 3923-3928.

[23] J. Gabert, E. Beillard, V.H. van der Velden, W. Bi, D. Grimwade, N. Pallisgaard, G. Barbany, G. Cazzaniga, J.M. Cayuela, H. Cave, F. Pane, J.L. Aerts, D. De Micheli, X. Thirion, V. Pradel, M. Gonzalez, S. Viehmann, M. Malec, G. Saglio and J.J. van Dongen, Standardization and quality control studies of 'real-time' quantitative reverse transcriptase polymerase chain reaction of fusion gene transcripts for residual disease detection in leukemia - a Europe Against Cancer program, Leukemia 17 (2003), 2318-2357.

[24] A. Bagg, R.M. Braziel, D.A. Arber, K.E. Bijwaard and A.Y. Chu, Immunoglobulin heavy chain gene analysis in lym- phomas: a multi-center study demonstrating the heterogeneity of performance of polymerase chain reaction assays, J. Mol. Diag. 4 (2002), 81-89.

[25] D. Xu, J. Du, C. Schultz, A. Ali and H. Ratech, Rapid and accurate detection of monoclonal immunoglobulin heavy chain gene rearrangement by DNA melting curve analysis in the Light Cycler system, J. Mol. Diag. 4 (2002), 216-222.

[26] N.S. Andersen, J.W. Donovan, J.S. Borus, C.M. Poor, D. Neuberg, J.C. Aster, L.M. Nadler, A.S. Freedman and J.G. Gribben, Failure of immunologic purging in mantle cell lymphoma assessed by polymerase chain reaction detection of minimal residual disease, Blood 90 (1997), 4212-4221.

[27] G.S. Hanekom, H.M. Stubbings, C.A. Johnson and S.H. Kidson, The detection of circulating melanoma cells correlates with tumor thickness and ulceration but is not predictive of metastasis for patients with primary melanoma, Melanoma Res 9 (1999), 465-473.

[28] B.J. Curry, K. Meyers and P. Hersey, Polymerase chain reaction detection of melanoma cells in the circulation: relationn to clinical stage, surgical treatment and recurrence from melanoma, J. Clin. Oncol. 16 (1998), 1760-1769.

[29] B. Mellado, D. Colomer, T. Castel, M. Muñoz, E. Carballo, M. Galán, J.M. Moscero, J.L. Lives Corrons, J.J. Grau and J. Estape, Detection of circulating neoplastic cells by RT-PCR in malignant melanoma. Correlation with clinical stage and prognosis, J. Clin. Oncol. 14 (1996), 2091-2097.

[30] P. Brossart, J.W. Shmier, S. Krüger, M. Wilhuck, C. Scheibenbogen, T. Mohler and V. Keilholz, A polymerase chain reaction-based semiquantitave assessment of malignant melanoma cells in peripheral blood, Cancer Res 55 (1995), 4065-4068.

[31] U. Kunter, J. Buer, M. Probst, S. Dvernsing, S. Dvernsing, I. Dallmann, J. Grosse, H. Kirchner, E.M. Schluepen, M. Volkenandt, A. Ganser and J. Atzpidien, Peripheral blood tyrosinase messenger RNA detection and survival in malignant melanoma, J. Natl. Cancer Inst. 88 (1996), 590-594.

[32] B. Farthmann, J. Eberle, K. Krasagakis, M. Gstöttner, N. Wang, S. Bisson and C.E. Orfanos, RT-PCR for tyrosinasemRNA positive cells in peripheral blood: Evaluation strategy and correlation with known prognostic markers in 123 melanoma patients, J Invest Dermatol 110 (1998), 263-267.

[33] J.P. Alao, M.Q. Mohammed, M.J. Slade and S. Retras, Detection of tyrosinase mRNA by RT-PCR in the peripheral blood of patients with advance metastatic melanoma, Melanoma Res 9 (1999), 395-399.

[34] G.G. Brownbridge, J. Gold and M. Edward, Evaluation of the use of tyrosinase-specific and melanA/MART-1 specific reverse transcriptase-coupled-polymerase chain reaction to detect melanoma cells in peripheral blood samples from 299 patients with malignant melanoma, Br. J. Dermatol. 144 (2001), 279-287.

[35] J. Hai-Ying, Y. Toshiharu, M. Yasushi, O. Fusayuki and J. Kowichi, Detection of tyrosinase and tyrosinase-related protein 1 sequences from peripheral blood of melanima patients using reverse transcription-polymerase chain reaction, J. Dermatol Scin. 33 (2003), 169-176.

[36] R. Glaser, K. Rass, S. Seiter, A. Hauschild, E. Christophers and W. Tilgen, Detection of circulating melanoma cells by specific amplification of tyrosinase complementary DNA is no a reliable tumor marker in melanoma patients, J. Clin. Oncol. 15 (1997), 2828-2825.

[37] G. Palmieri, P.A. Ascierto, F. Perrone, S.M. Satriano, A. Ottaiano, A. Daponte, M. Napolitano, C. Caraco, N. Mozzillo, M.T. Melucci, A. Cossu, F. Tanda, C. Gallo, R.A. Satriano and 
G. Castello, Prognostic value of circulating melanoma cells detected by reverse transcriptase-polymerase chain reaction, J. Clin. Oncol. 21 (2003), 757-759.

[38] H. Tsao, U. Nadiminti, A.J. Sober and M. Bigby, A metaanalysis of reverse transcriptase-polymerase chain reaction for tyrosinase mRNA as a marker for circulating tumor cells in cutaneous melanaoma, Arch. Dermatol. 137 (2001), 325-330.

[39] W.H. Clark, Tumor progression and the nature of cancer, $B r$. J. Cancer 64 (1991), 631-644. 


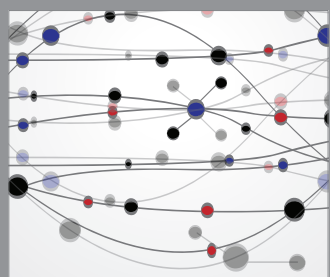

The Scientific World Journal
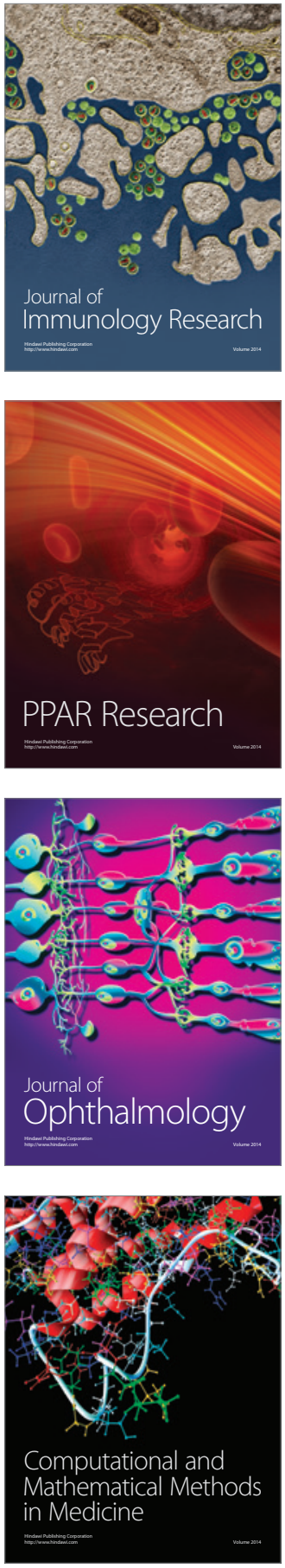

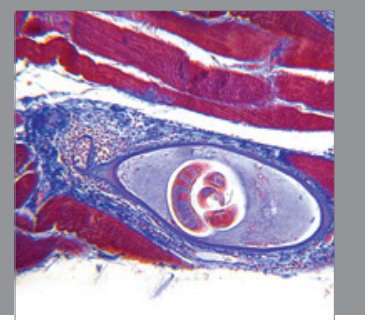

Gastroenterology

Research and Practice
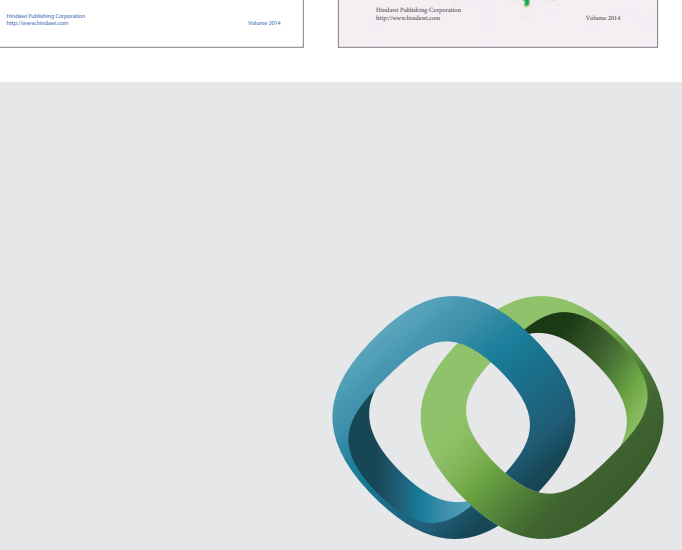

\section{Hindawi}

Submit your manuscripts at

http://www.hindawi.com
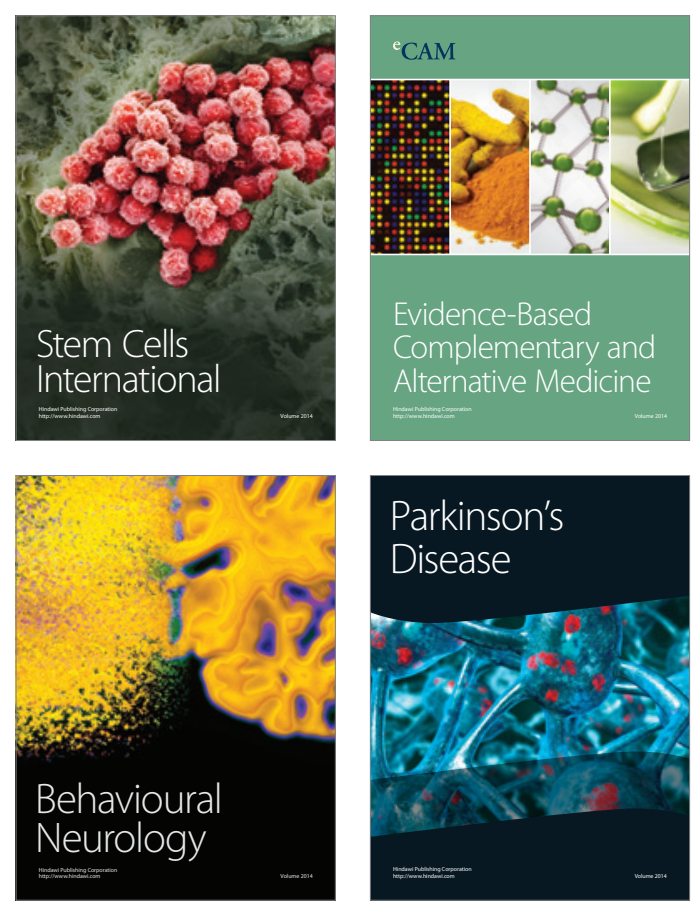

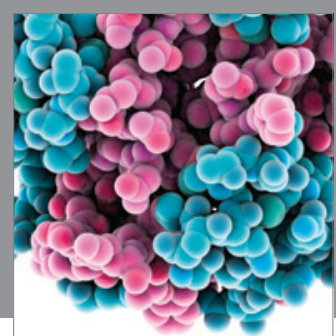

Journal of
Diabetes Research

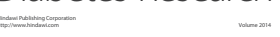

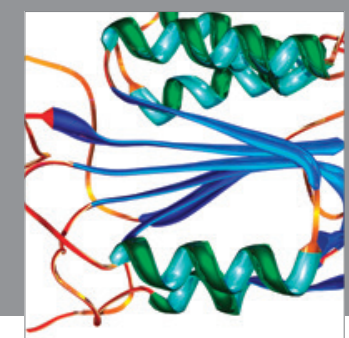

Disease Markers
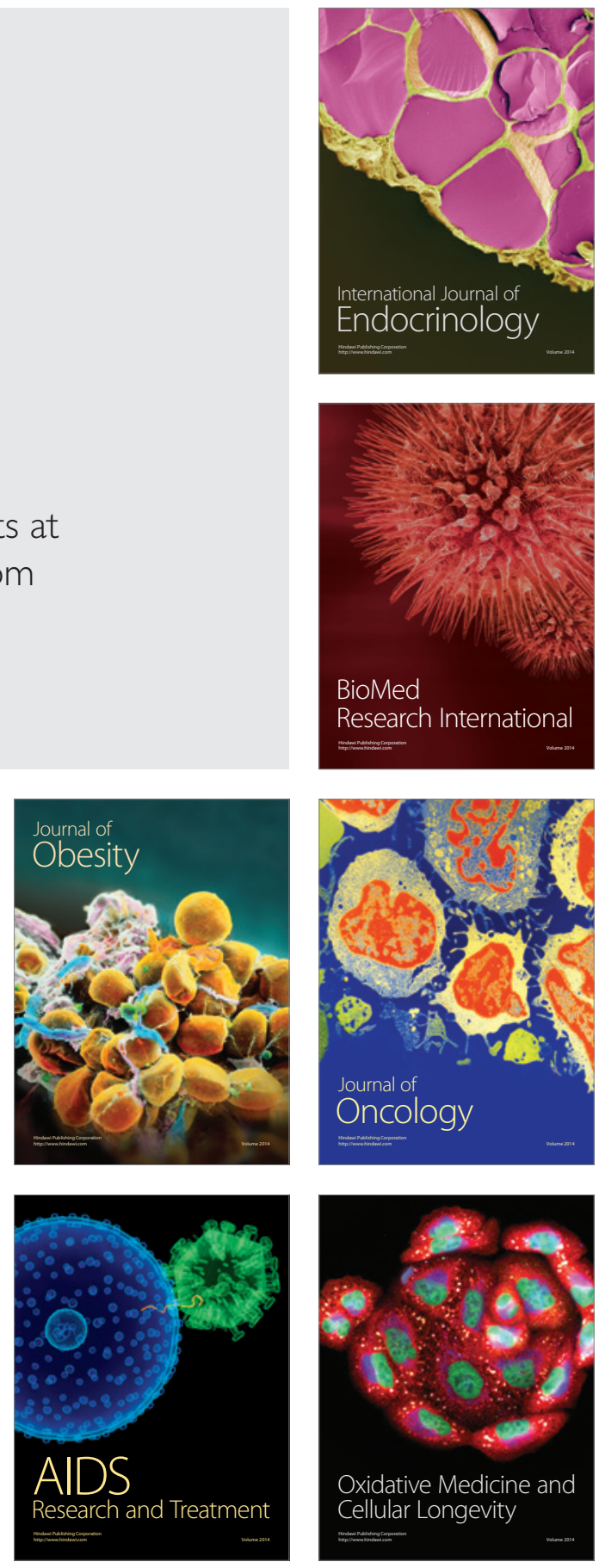